\title{
Soy pinitol acts partly as an insulin sensitizer or insulin mediator in 3T3-L1 preadipocytes
}

\author{
Gyeong-Min Do $\cdot$ Myung-Sook Choi $\cdot$ Hye-Jin Kim $\cdot$ \\ Myung-Nam Woo $\cdot$ Mi-Kyung Lee $\cdot$ Seon-Min Jeon
}

Published online: 27 November 2007

(c) Springer-Verlag 2007

\begin{abstract}
The blood glucose-lowering property of pinitol is mediated via the insulin signaling pathway. This study was carried out to evaluate the effects of soy pinitol on adipogenesis in a 3T3-L1 cell line; 3T3-L1 preadipocytes were treated with pinitol $(0-1 \mathrm{mM})$ together with insulin for 9 days. The regulation of lipid metabolism was assessed by oil-red-O staining of intracellular lipids and realtime PCR of adipogenesis-related factors. The inhibition of cell proliferation was estimated by MTT assay. Pinitol treatment did not inhibit lipid accumulation, nor did it affect expression of adipogenesis-related factors, including ADD1, aP2 and FAS, in a dose-dependent manner. Expression of adiponectin, GLUT4, IRS, C/EBP $\alpha$ and $\operatorname{PPAR} \gamma$ mRNAs, however, increased in cells treated with $0.5 \mathrm{mM}$ and/or $1 \mathrm{mM}$ pinitol. Pinitol treatment did not affect the inhibition of cell growth and proliferation in a dose-dependent manner. Accordingly, we suggest that pinitol is nontoxic to this cell line, and that it enhances adipogenesis by acting as an insulin sensitizer or insulin
\end{abstract}

G.-M. Do · M.-S. Choi · H.-J. Kim - M.-N. Woo

Department of Food Science and Nutrition,

Kyungpook National University,

Daegu, Kyoungsangbuk-do 702-701,

Republic of Korea

M.-K. Lee

Department of Food Science and Nutrition,

Sunchon National University,

Suncheon, Jeonranam-do 540-742,

Republic of Korea

S.-M. Jeon $(\square)$

Institute of Genetic Engineering,

Kyungpook National University,

1370 San-kyuk dong, Buk-ku, Daegu,

Kyoungsangbuk-do 702-701, Republic of Korea

e-mail: smjeon@knu.ac.kr mediator via the upregulation of adiponectin, GLUT4, IRS, $\mathrm{C} / \mathrm{EBP} \alpha$ and $\mathrm{PPAR} \gamma$ in 3T3-L1 preadipocytes.

Keywords Soy pinitol $\cdot 3 \mathrm{~T} 3$-L1 preadipocytes . adipogenesis · Oil-red-O staining · Real-time PCR . MTT assay

\section{Introduction}

Adipose tissue consists of adipocytes, which store triacylglycerol as a fuel for the body. Excess adipose tissue leads to insulin resistance, thereby increasing the risk of type 2 diabetes and cardiovascular diseases [1]. In many obesityrelated studies, the fibroblastic 3T3-L1 preadipocyte line is widely used to investigate the mechanism of preadipocyte proliferation and adipocyte genesis, due to the ability of this cell line to undergo complete differentiation into mature adipocytes, which differentiate according to a program coordinated by adipogenic molecules, including a variety of growth factors, cytokines and hormones [2, 3]. Insulin promotes lipogenesis and inhibits lipolysis when treated with appropriate agents such as dexamethasone and isoutylmethylxanthine (IBMX). The 3T3-L1 preadipocytes change from an extended fibroblast-like morphology to a round morphology with cytoplasmic lipid vesicles made from newly biosynthesized triglycerides [4].

D-Chiro-inositol (DCI) - recently found in inositol phosphoglycan - is thought to be a mediator of insulin signaling pathways and to be involved in glycosylphosphatidyl-inositol protein anchors [5]. DCI is obtained mostly from dietary pinitol (3-O-methyl-D-chiroinositol), a methylated derivative of DCI. Pinitol is a prominent component of dietary legumes, soy and pine trees [6]. Some reports have reported a hypoglycemic effect of 
pinitol-it affects glucose uptake via a postreceptor pathway of insulin action in normal, STZ-diabetic rats [7]. Bates et al. [8] reported that D-pinitol provides a substrate for the phosphatidylinositol-3-kinase (PI3K)-mediated step of insulin signaling, thereby enhancing a very weak insulin signal and action in order to mimic, in part, the PI3K pathway of insulin action. However, it has been also reported that pinitol does not improve the action of insulin in carbohydrate- or fat-metabolism [9]. On the other hand, pinitol has been suggested to possess various biological effects, including anti-inflammatory [10], cardiovascular disease-preventing [11], and creatine retention promotion properties [12]. Reaven et al. [13] reported that dietary pinitol as a supplement may be recommended to help maintain normal metabolic functions.

In the present study, we investigated the effects of pinitol on the regulation of cell differentiation and adipogenesis by using oil-red-O staining, quantitative real-time PCR, and an MTT assay in 3T3-L1 preadipocytes.

\section{Material and methods}

\section{Cell culture and treatments}

Mouse embryo 3T3-L1 cells (American Type Culture Collection, Rockville, MD) were cultured in Dulbecco's modified Eagle's medium (DMEM), which was supplemented with $10 \%$ fetal calf serum (FCS) and penicillin/ streptomycin at $37^{\circ} \mathrm{C}$ in $5 \% \mathrm{CO}_{2}$. After the 3T3-L1 cells became confluent, the medium was replaced with differentiation medium (DM) containing $10 \%$ fetal bovine serum (FBS), $1 \%$ penicillin/streptomycin, $10 \mu \mathrm{g} / \mathrm{ml}$ insulin, $1 \mu \mathrm{M}$ dexamethasone (Sigma, St. Louis, MO), and $0.5 \mathrm{mM}$ IBMX (Sigma, St. Louis, MO), and cultured for 2 days. The cell medium was then replaced with $10 \%$ FBS plus $10 \mu \mathrm{g} / \mathrm{ml}$ insulin only, and the cells were fed every 2 days with the same medium. At 9 days after differentiation, the cells were either harvested for real-time PCR or stained with oil-Red-O. Pinitol (Fig. 1) was purchased from Amicogen (Jinju, Korea) and cells were treated different

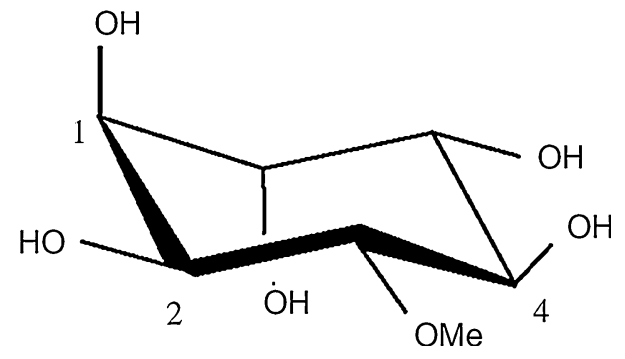

Fig. 1 The structure of pinitol doses of pinitol (0-1 $\mathrm{mM})$ for 9 days during differentiation after confluence.

\section{Oil-red-O staining}

To determine the state of adipose differentiation by visual inspection, the cells were washed with phosphate-buffered saline (PBS) twice, fixed with $10 \%$ formalin at room temperature for $10 \mathrm{~min}$, and stained with $0.5 \%$ oil-red-O (Sigma) for $1 \mathrm{~h}$. After staining, the cultures were rinsed several times with $70 \%$ ethanol. Pictures were taken using an Olympus (Tokyo, Japan) microscope.

Quantitative real-time reverse transcriptase-polymerase chain reaction

Total RNA from cultured 3T3-L1 cells was isolated with TRIzol reagent (Invitrogen, Carlsbad, CA) according to the manufacturer's protocol, and RNA was treated with DNaseI at room temperature for $15 \mathrm{~min}$ to remove genomic DNA contamination. First strand cDNA was synthesized using a cDNA synthesis kit (Promega, Madison, WI). Gene expression levels were analyzed by quantitative real-time reverse transcriptase-polymerase chain reaction (RT-PCR) using a ABI 7500 Real Time PCR system (Applied Biosystems, Foster city, CA). The primers used in the experiments are shown in Table 1 . After an initial incubation for $2 \mathrm{~min}$ at $50^{\circ} \mathrm{C}$, cDNA was denatured at $95^{\circ} \mathrm{C}$ for $10 \mathrm{~min}$. The results shown were from at least three independent experiments. The mRNA levels of all genes were normalized using GAPDH as an internal control.

\section{Cytotoxicity assay}

Growth inhibition by pinitol was determined by MTT assay [14]. Before treatment, cells were first grown overnight on a 96 well plate at a density of $1 \times 10^{4}$ cells/well. After $24 \mathrm{~h}$, various concentrations of pinitol (0-1 mM) were applied to the cells in serum-free DMEM, and cells were incubated for an additional $48 \mathrm{~h}$ at $37^{\circ} \mathrm{C}$. After $48 \mathrm{~h}$ of oxidant treatment of cells, the culture medium was aspirated under vacuum, and $200 \mu \mathrm{l}$ MTT $(1 \mathrm{mg} / \mathrm{ml})$ was added and further incubated for $4 \mathrm{~h}$ at $37^{\circ} \mathrm{C}$. The MTT solution was discarded by aspirating, and the resulting formazan product, which was converted by viable cells, was dissolved in $150 \mu \mathrm{l}$ dimethylsulfoxide. The absorbance was read by an ELISA plate reader at $540 \mathrm{~nm}$ with a $620 \mathrm{~nm}$ reference. Cell viability, or the inhibition of cell population growth, is expressed as a percentage of the absorbance seen in untreated control cells. 
Table 1 Primer sequences used for real-time PCR. GLUT4 Glucose transporter 4, IRS insulin receptor substrate, $P P A R \gamma$ peroxisome proliferators-activated receptor $\gamma, C / E B P \propto$ CCAAT/enhancer-binding protein $\alpha, A D D 1$ adipocyte determination- and differentiation-dependent factor $1, a P 2$ adipocyte bindgin protein aP2, FAS fatty acid synthase, GAPDH glyceraldehyde-3-phosphate dehydrogenase

\begin{tabular}{lll}
\hline Gene & Forward primer & Reverse primer \\
\hline Adiponectin & ACGAGGGATGCTACTGTTGC & AAGCCCCCATACCAAATGT \\
GLUT4 & GCCCCACAGAAGGTGATTGA & AGCGTAGTGAGGGTGCCTTG \\
IRS & ATTGCTGGACAGTCTCCTC & CTTTTTCTTCACGAATGTCC \\
PPAR $\gamma$ & AGAGTCTGCTGATCTGCGAGC & TTCCTGTCAAGATCGCCCTC \\
C/EBP $\alpha$ & AAGAACAGCAACGAGTACC & AACTCCAGCACCTTCTGTT \\
ADD1 & TGCCATGGGCAAGTACACAG & TTGCCATGGTATAGCATCTCCT \\
aP2 & AGCATCATAACCCTAGATGG & AAACTCTTGTGGAAGTCACG \\
FAS & GTGAAGAAGTGTCTGGACTGTGTCAT & TTTTCGCTCACGTGCAGTTTA \\
GAPDH & TGCAGTGGCAAAGTGGAAT & TTGAATTTGCCGTGAGTGGA \\
\hline
\end{tabular}

Statistical analysis

Statistical analysis was performed using the SPSS 11.5 program package. Data were expressed as mean $\pm \mathrm{SD}$. Analysis of variance was performed using ANOVA procedures. Significant differences $(P<0.05)$ between the means were determined by Duncan's multiple range tests.

\section{Results}

Effect of pinitol on lipid accumulation in 3T3-L1 adipocytes

To test whether pinitol inhibits adipocyte differentiation, we used a DM medium containing insulin, dexamethasone and IBMX to induce 3T3-L1 preadipocyte differentiation. During DM induction, soy pinitol was added to the medium at day 0 to observe its effects on 3T3-L1 adipocyte differentiation; lipid accumulation and adipocytes were assessed by staining with oil-red-O on day 9. At concentrations reanging from 0.05 to $1 \mathrm{mM}$, pinitol did not alter adipocyte differentiation or adipogenesis (Fig. 2).

Effect of pinitol on mRNA expression of adipogenesisrelated factors in 3T3-L1 adipocytes

Figure 3 summarizes the expression of adipogenesis-related factor genes as tested by real time RT-PCR analysis.
Adiponectin mRNA levels were highest in cells treated with $1 \mathrm{mM}$ pinitol (Fig. 3a), and those of the glucose transporter 4 (GLUT4), insulin receptor substrate (IRS), peroxisome proliferators-activated receptor $\gamma(\operatorname{PPAR} \gamma)$ and CCAAT/enhancer-binding protein $\alpha(\mathrm{C} / \mathrm{EBP} \alpha)$ were increased in cells treated with 0.5 and $1 \mathrm{mM}$ pinitol (Fig. 3b-e). However, expression of the adipocyte determination- and differentiation-dependent factor 1-sterolregulatory element-binding protein 1c (ADD1/SREBP1c), adipocyte bindgin protein $\mathrm{aP} 2$, and fatty acid synthase (FAS) genes were not significantly different upon addition of different concentrations of pinitol (Fig. $3 \mathrm{f}-\mathrm{h}$ ).

Effect of pinitol on inhibition of cell population growth in 3T3-L1 preadipocytes

To assess whether pinitol inhibited the population growth of 3T3-L1 cells, preadipocytes were treated with $0-1 \mathrm{mM}$ pinitol and the cell population growth was determined using a MTT assay. As shown in Fig. 4, pinitol did not affect cell population growth in a time- or dose-dependent manner. Therefore, it was concluded that pinitol did not induce cytotoxic responses.

\section{Discussion}

Adipogenic capacity is affected by the combined effect of proadipogenic and antiadipogenic hormones and growth
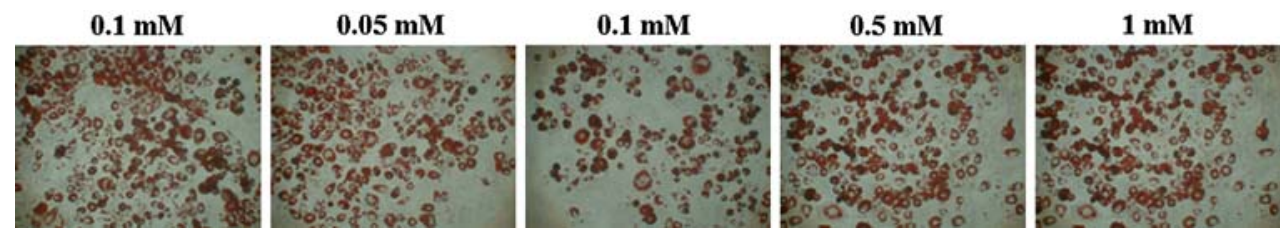

Fig. 2 Pinitol slightly inhibits 3T3-L1 differentiation induced by differentiation medium (DM). The cells were stained with oil-red-O at day 9. Pinitol (0-1 mM) was added at the beginning of DM induction of 3T3-L1 cells, with additional treatment every 2 days 
Fig. 3 Real time reverse transcriptase coupled polymerase chain reaction (RTPCR) analysis of several adipogenesis-related factors. mRNAs were quantified using GAPDH as an internal standard.

The results represent means $\pm \mathrm{SD}(n=5)$
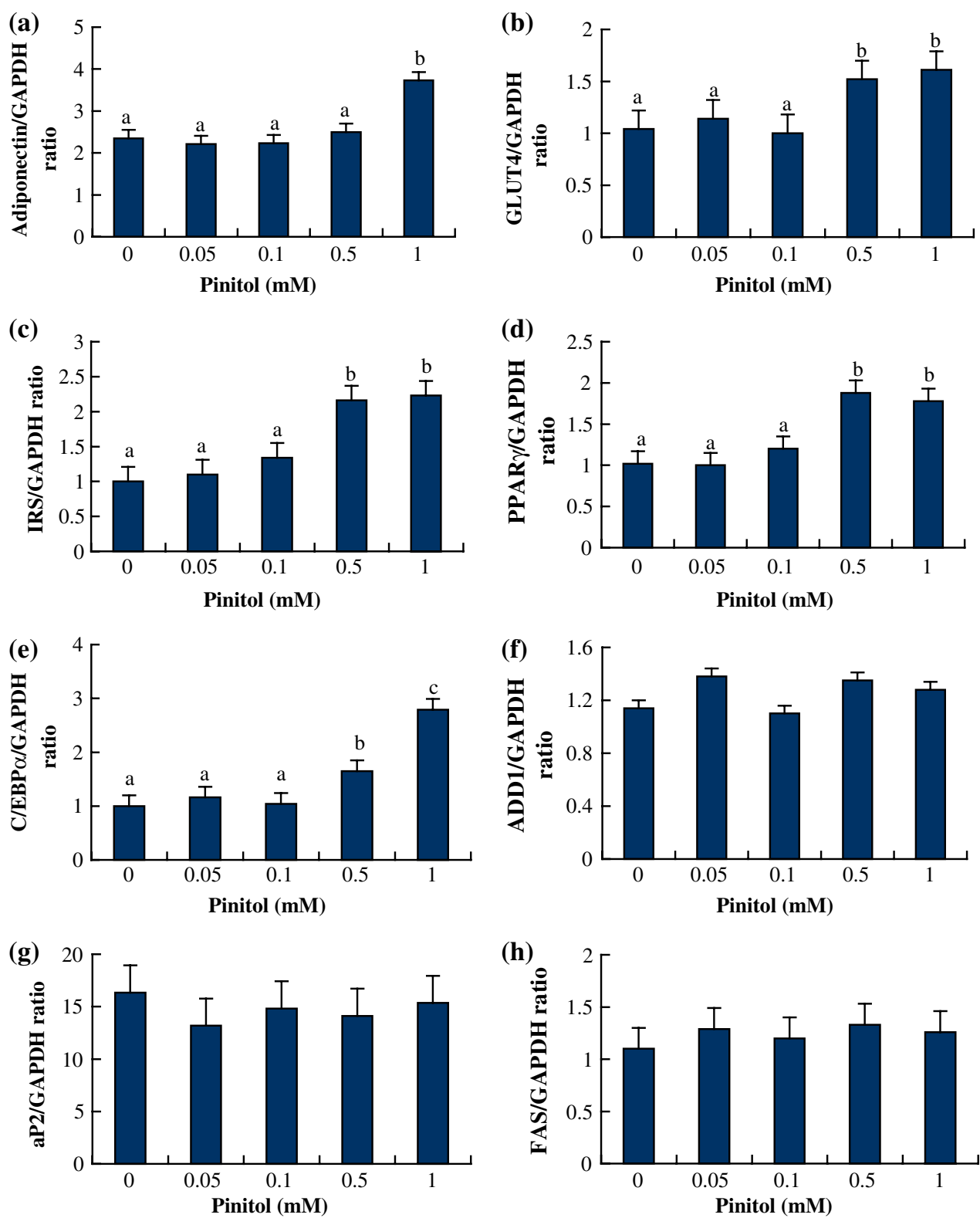

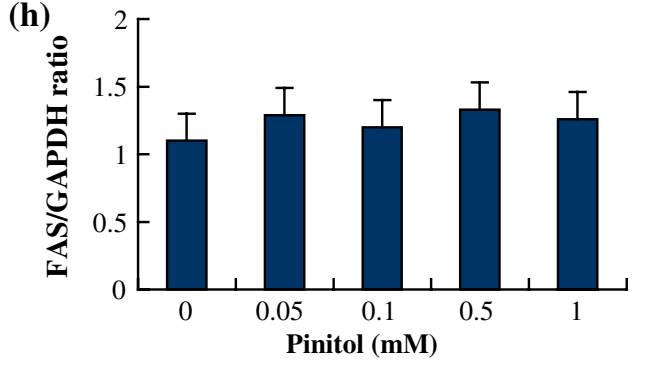

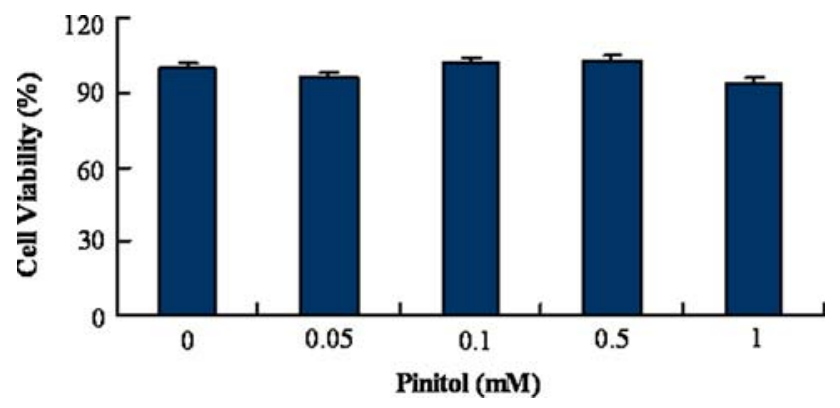

Fig. 4 Effect of pinitol on the inhibition of cell population growth in 3T3-L1 preadipocytes. Cells were treated with $0-1 \mathrm{mM}$ pinitol for 9 days. Reported values are means $\pm \operatorname{SD}(n=5)$ factors. Following induction of adipogenesis, preadipocytes upregulate key adipogenic transcription factors including $\mathrm{C} / \mathrm{EBP} \alpha, \mathrm{PPAR} \gamma$ and ADD1/SREBP1c [15-17]. $\mathrm{C} / \mathrm{EBP} \alpha$ plays a regulatory role in adipocyte differentiation through increases expression during the adipose conversion of 3T3-L1 preadipocytes, and expression of $\mathrm{C} / \mathrm{EBP} \alpha$ induces the coordinate expression of a group of adipocyte genes (i.e., aP2, GLUT4, IRS) [18, 19]. PPAR $\gamma$ was originally shown to play an important role in adipocyte differentiation, glucose homeostasis and insulin signaling; PPAR $\gamma$ agonists are useful in the treatment of patients with type 2 diabetes, because they stimulate adipogenesis and, at the same time, reduce insulin resistance [20]. Recently, it was reported that PPAR $\gamma$ mRNA expression in the adipose 
tissue of humans was inversely associated with cardiovascular risk factors, and that there was a significant association between PPAR $\gamma$ polymorphism and coronary artery disease [21]. ADD1/SREBP1c plays a crucial role in fatty acid metabolism and insulin-dependent gene regulation, especially in the regulation of lipogenic gene expression in fat and liver for whole body energy homeostasis [17, 22]. In this study, 0.5 and $1 \mathrm{mM}$ pinitol upregulated the expression of PPAR $\gamma$ and $\mathrm{C} / \mathrm{EBP} \alpha$ mRNAs without altering the gene expression of ADD1/SREBP1c. Notably, PPAR $\gamma$ agonists or synthetic ligands of PPAR $\gamma$ result in both increased gene expression and increased circulating levels of adiponectin [23, 24]. Our results show that pinitol treatment increase adiponectin gene expression-an adipocytokine shown to possess antidiabetic, antiatherogenic and anti-inflammatory properties [25]. Insulin also increases the expression of adiponectin [26], and perhaps the insulin-like pinitol affected the upregulation of adiponectin gene in this study.

It is well established that insulin promotes the translocation of the insulin responsive glucose transporter, GLUT4, from the intracellular compartment to the plasma membrane [27]. The binding of insulin to its receptor triggers the phosphorylation of insulin receptor substrate (IRS) proteins. Tyrosine phosphorylated IRS proteins recruit and sequentially activate PI3K [28], which is one of the key components of the insulin signaling pathway. Hence, there is great interest in glucose transport and PI3K signaling in diabetes mellitus. Pinitol also increased GLUT4 and IRS gene expression, perhaps due to its insulin-mimicking property. Pinitol, however, did not alter the expression of the aP2 and FAS genes, which are related to adipocyte differentiation [29] and de novo lipogenesis via synthesis of long-chain fatty acids from acetyl-CoA and malonyl-CoA [30], respectively.

There are currently no known examples of any adverse side effects arising from the use of pinitol at recommended dosage levels [6, 31]. In this study, the results of the MTT assay clearly indicated that pinitol did not inhibit cell population growth of 3T3-L1 preadipocytes (Fig. 4).

In conclusion, this study reports that soy pinitol did not block adipocyte differentiation, proliferation or lipid accumulation in a dose-dependent manner, and that most factors related to adipogenesis and glucose transport were upregulated by pinitol treatment in real-time RT-PCR assays, although there was no alteration in the expression of aP2, ADD1/SREBP1c or FAS mRNA. Accordingly, we suggest that pinitol may improve glucose transport and insulin sensitivity because high-dose pinitol treatment $(0.5$ and $1 \mathrm{mM}$ ) enhanced the expression of adiponectin, GLUT4, IRS, C/EBP $\alpha$, and PPAR $\gamma$ mRNA, as a putative insulin mediator or insulin sensitizer. These effects are believed to be similar to those of $\operatorname{PPAR} \gamma$ agonists; supplementation with dietary pinitol may help in the prevention and therapy of type 2 diabetes.

Acknowledgments This work was supported by the Korea Research Foundation grant by the Korean Government (MOEHRD)(R08-2004-000-10499-0) and the second-phase of BK21 (Ministry of Education, Republic of Korea).

\section{References}

1. Saltiel AR, Kahn CR (2001) Insulin signaling and the regulation of glucose and lipid metabolism. Nature 414:799-806

2. Cowherd RM, Lyle RE, McGehee RE Jr (1999) Molecular regulation of adipocyte differentiation. Cell Develop Biol 10:3-10

3. MacDougald OA, Mandrup S (2002) Adipogenesis forces that tip the scales. Trends Endocrinol Metab 13:5-11

4. Green H, Kehinde O (1974) Sublines of mouse $3 T 3$ cells that accumulate lipid. Cell 1:113-116

5. Holman GD, Kasuga M (1997) From receptor to transporter: insulin signaling to glucose transport. Diabetologia 40:1001-1003

6. Ostlund et al (1996) United States Patent. Patent Number 5,550,166. August 277

7. Huang LC, Fonteles MC, Houston DB, Zhang G, Larner J (1993) Chiroinositol deficiency and insulin resistance. III. Acute glycogenic and hypoglycemic effects of two inositol phosphoglycan insulin mediators in normal and streptozotocin-diabetic rats in vivo. Endocrinology 132:652-657

8. Bates SH, Jones RB, Bailey CJ (2000) Insulin-like effect of pinitol. Br J Pharmacol 130:1944-1948

9. Campbell WW, Haub MD, Fluckey JD, Ostlund RE Jr, Thyfault JP, Morse-Carrithers H, Hulver MW, Birge ZK (2004) Pinitol supplementation does not affect insulin-mediated glucose metabolism and muscle insulin receptor content and phosphorylation in older human. J Nutr 134:2998-3003

10. Singh RK, Pandey BL, Tripathi M, Pandey VB (2001) Antiinflammatory effect of (+)-pinitol. Firoterapia 72:168-170

11. Kim JI, Kim JC, Kang MJ, Lee MS, Kim JJ, Cha IJ (2005) Effects of pinitol isolated from soybeans on glycemic control and cardiovascular risk factors in patients with type 2 diabetes mellitus: a randomized controlled study. Eur J Clin Nutr 59:456-458

12. Greenwood M, Kreider RB, RasMussen C, Almada AL, Earnest CP (2001) D-Pinitol augments whole body creatine retention in man. J Exer Physiol 4:41-47

13. Reaven G (1995) Pathophysiology of insulin resistance in human disease. Physiol Rev 75:473-486

14. Mosmann T (1983) Rapid colorimetric assay for cellular growth and survival: application to proliferation and cytotoxicity assays. J Immunol Methods 65:55-63

15. Cao Z, Umek RM, Mcknight SL (1991) Regulated expression of three C/EBP isoforms during adipose conversion of 3T3-L1 cells. Genes Dev 5:1538-1552

16. Zhu Y, Qi C, Korenberg JR, Chen XN, Noya D, Rao MS, Reddy JK (1995) Structural organization of mouse peroxisome proliferators-activated receptor $\gamma(\mathrm{mPPAR} \gamma)$ gene: altenative promoter use and different splicing yield two mPPAR $\gamma$ isoforms. Proc Natl Acad Sci USA 92:7921-7925

17. Kim JB, Spiegelman BM (1996) ADD1/SREBP1 promotes adipocyte differentiation and gene expression linked to fatty acid metabolism. Genes Dev 10:1096-1107

18. Birkenmeier EH, Gwynn B, Howard S, Jerry J, Gordon JI, Landschulz WH, McKnight SL (1989) Tissue-specific expression, developmental regulation and genetic mapping of the gene 
encoding CCAAT/enhancer binding protein. Genes Dev 3:11461156

19. Christy RJ, Kaestner KH, Gelman DE, Lane MD (1991) CCAAT/ enhancer binding proteins gene promoter: binding of nuclear factors during differentiation of 3T3-L1 preadipocytes. Proc Natl Acad Sci USA 88:2593-2597

20. Kersten S, Desvergne B, Wahli W (2000) Roles of PPARs in health and disease. Nature 405:421-424

21. Krempler F, Breban D, Oberkofler H, Esterbauer H, Hell E, Paulweber B, Patsch W (2000) Leptin, peroxisome proliferatorsactivated receptor- $\gamma$, and CCAAT/enhancer binding protein $\alpha$ mRNA expression in adipose tissue of humans and their relation to cardiovascular risk factors. Arterioscler Thromb Vasc Biol 20:443-449

22. Foretz M, Guichard C, Ferre P, Foufelle F (1999) Sterol regulatory element binding protein-1c is a major mediator of insulin action on the hepatic expression of glucokinase and lipogenesisrelated gene. Proc Natl Acad Sci USA 96:12737-12742

23. Maeda N, Takahashi M, Funahashi T, Kihara S, Nishizawa H, Kishida K, Nagaretani H, Matusuda M, Komuro R, Ouchi N, Kuriyama H, Hotta K, Nakamura T, Shimomura I, Matsuzawa Y (2001) PPARgamma ligands increase expression and plasma concentrations of adiponectin, an adipose-derived protein. Diabetes 50:2094-2099

24. Sharabi Y, Oron-Herman M, Kamari Y, Avni I, Peleg E, Shabtay Z, Grossman E, Shamiss A (2007) Effect of PPAR- gamma agonist on adiponectin levels in the metabolic syndrome: lessons from the high fructose fed rat model. Am J Hyperten 20:206-210

25. Pajvani UB, Du X, Combs TP, Berg AH, Rajala MW, Schelthess T, Engel J, Brownlee M, Scherer PE (2003) Structure-function studies of the adipocyte-secreted hormone Acrp30/adiponectin. Implications for metabolic regulation and bioactivity. J Biol Chem 278:9073-9085

26. Scherer PE, Williams S, Fogliani M, Baldini G, Lodish HF (1995) A novel serum protein similar to C1q, produced exclusively in adipocytes. J Biol Chem 270:26746-26749

27. Shepherd PR, Kahn BB (1999) Glucose transporters and insulin action-implications for insulin resistance and diabetes mellitus. New Engl J Med 341:248-257

28. Czech MP (2002) Fat targets for insulin signaling. Mol Cell 9:695-696

29. Rosen ED, Scarraf P, Troy AE, Bradwin G, Moore K, Milstone DS, Spiegelman BM, Mortensen RM (1999) PPAR $\gamma$ is required for the differentiation of adipose tissue in vivo and in vitro. Mol Cell 4:611-617

30. Wakil S (1989) Fatty acid synthase, a proficient multifunctional enzyme. Biochemistry 28:4523-4530

31. Narayanan C (1987) Pinitol-a new anti-diabetic compound from the leaves of Bougainvillea. Curr Sci 56:76-78 